\title{
Collaborating on Electronic Course Reserves to Support Student Success
}

\author{
Elaine Magusin \\ Kay Johnson \\ Athabasca University
}

\begin{abstract}
As we move into an era in which an increasing amount of information is available in digital form and more universities and colleges are providing distance education courses, electronic course reserves are becoming an essential part of library services. The Digital Reading Room (DRR), an Athabasca University collaboratively developed ereserves system, facilitates immediate student access to faculty selected, course specific resources in a variety of media and promotes increased use of electronic information resources. To encourage student success in a digital environment, the Library has worked with Faculty to create information literacy tools designed to help students become better researchers and information consumers.
\end{abstract}

\section{Introduction}

As librarians discover, develop, and implement best practices for delivering services and resources to distance learners, one area that has seen considerable experimentation is electronic course reserves. Whether we use commercial products such as Docutek's ERes or in-house systems, we face similar challenges in bringing the course reserves desk to the desktops of our students. Technology offers many possibilities, but providing convenient access to resources that teaching faculty have prescribed for a course is only the beginning. "Student success" is a lofty goal, and the one we reach for, as librarians, teaching faculty, and other institutional partners work together to ensure that students not only have access to resources, but are provided with opportunities to grow as independent life long learners. Athabasca University's Digital Reading Room project offers one model for delivering e-reserves and learner support.

\section{From Print to Electronic}

Athabasca University (AU) delivers distance and online education across Canada and internationally to over 26,000 students, and offers over 500 individual courses and approximately 60 programs at masters, bachelors, diploma and certificate levels. AU offers undergraduate courses primarily in individualized study mode, with online grouped study representing the primary mode of delivery at the graduate level.

When students register in a course at $\mathrm{AU}$, their course package, containing resources such as textbooks, study guides, student manuals, assignment manuals, and reading files, is automatically sent to them. Students are also generally required to use material beyond the contents of the course package. Many course study guides list "Supplementary Materials", a resource list that encourages students to further investigate various topics. Students are directed to contact the Library to request Supplementary Materials, which may be photocopied articles, books or audio-visual resources, and are intended to help them in completing course assignments, writing papers, or expanding their knowledge of the course content. Master copies of reproducible readings are filed in Supplementary Materials cabinets, and are photocopied upon request and sent out to students through the postal system at the Library's expense.

Delivery of instruction and learner support has evolved in response to advances in information and communication technologies. As AU undergraduate courses are revised and updated the goal, expressed in 
the Strategic University Plan, is to include "proven, online-learning and online-assessment activities and resources", using "appropriate e-learning pedagogy". The objective for the Library is to "increasingly provide support to students using digital resources by acquiring and developing online resources and deploying resources (human and other) to facilitate learner access" (Athabasca University, 2002, p. 11). With demand for access to digital resources growing at the undergraduate level, as well as at the graduate level with the introduction of new programs, the Library initiated a project in 2002 to develop an electronic course reserves system to enhance, and in some cases replace, the traditional Supplementary Materials system.

In 1999 the Library explored the course reserves and electronic reserves capabilities of the Innovative Interfaces Inc. library system. The initial plan was to enter course reserves data (bibliographic citations) for the Supplementary Materials Lists (SMLs) for courses with more than 150 enrolments and/or high library use. Given that the number of journal database providers offering full text had grown and that online content appeared more stable, the Library anticipated that creating persistent links to the databases would be the preferred method of offering supplementary material online. It was recognized that much of the print based supplementary material on file would not be available through the databases and that this material would need to be scanned and mounted online in order for delivery to be electronic. Some ereserves work was completed, but the project bogged down due to a number of variables including demands on library staff time, the costs and time associated with obtaining copyright clearance for digitization of print based resources, and minimal faculty involvement or student interest. By 2002 the decision was made to abandon this project and to develop a more effective, flexible system, one that would capture the imaginations of the teaching faculty and better serve student needs: the Digital Reading Room (DRR).

\section{What is The Digital Reading Room?}

The Digital Reading Room (http://library.athabascau.ca/drr/) is an electronic course reserves system developed in-house using open source software. It provides for electronic search and retrieval of course and supplementary resources selected by teaching faculty. The DRR consists of a "Student View" in which students can access resources and an "Admin View" in which "Digital Reading Files" are created for courses, and faculty are provided with a means for easily updating the files. A Digital Reading File may be divided into "Required Readings" and "Supplementary Materials" and further partitioned into units, lessons or weeks that correspond with the study schedule for the course. Areas are provided for course descriptions, links to course or Library pages, and DRR help files. Resources in the DRR are identified by media type such as Web site, audio clip, video clip, PDF, table, diagram, or database article and may include annotations, descriptions or instructions.

The DRR operates along the principal of open access and is in this respect quite different from many other e-reserve systems. There are, of course, different levels of access. The DRR and the Digital Reading Files, and some of their contents, are accessible to the public. Access to articles from licensed databases requires authentication through the Library's proxy server. Professors may elect to password protect certain materials such as lecture notes. The rationale behind this openness is that the DRR is meant to function as a multidisciplinary knowledge database. The Library's traditional Supplementary Materials system is very closed. A student registered in a women's studies course receives a study guide that contains a Supplementary Materials List for that particular course. But, what if there is another women's studies course, or a psychology course, or a business course that has a Supplementary Materials List of use to that student? It may also happen that a professor who is writing a course could benefit from accessing materials filed away under other courses in the Supplementary Materials cabinets, but the task of browsing through these cabinets is too daunting. The DRR has a search engine that makes it possible for students and faculty to search across Reading Files and access faculty-selected resources from other courses.

As courses are developed and revised Digital Reading Files are being built into course structures replacing and/or enhancing the traditional Supplementary Materials system. The DRR currently supports more than 50 courses at the undergraduate and graduate levels and contains more than 3000 online learning resources and course materials. Both of these numbers are continually growing. 


\section{Collaboration and the DRR}

The Library's initial e-reserves project was a "library project". The DRR is a collaborative project involving the Library, the Educational Media Development (EMD) unit and teaching faculty. Librarians have performed key roles in developing the DRR. The Director of Library Services, acting as project director, has overseen all stages of the project, and his responsibilities include liaising with management and securing funding for resources and infrastructure. His task is to further the Library's progress in meeting the University's online learning goals, to bring faculty and staff on board the DRR project, and to continue the transition from "ownership to access", migrating from a print-based collection to one that is more digital. One of the key elements of his role is to translate the vision and use of the DRR from a useful electronic reserves tool to a University-wide system for incorporating digital resources, and searching and researching into the curriculum.

The Electronic Resources Librarian, as the project leader, has conceptualized and established the technical requirements of the project and coordinates the activities of the DRR developers. His responsibilities include providing strategic planning, marketing, and end-user training. The Reference Librarians, acting as consultants, provide feedback regarding integration of the DRR with public services library operations and test and critique the user friendliness of the DRR interface and functions.

The University's Educational Media Development unit has played a crucial role in the collaboration. The Director of EMD recognized the potential of the DRR to increasingly become an important component in relation to course packages, enhancing and, in some cases, replacing the Supplementary Materials List and she supported the project through the contributions of a number of EMD staff. An Instructional Webspace Designer has brought his expertise to the database and interface design, programming using HTML, CSS and JavaScript for the front-end and PHP scripting language and MYSQL database software for the back-end. The project has also benefited from the input and assistance of a visual designer, the AU Photographer, a course materials editor, an instructional media analyst, and the Copyright Officer.

From the beginning, and throughout the project, AU Faculty have played a consulting role in the development of the DRR, particularly its "Admin View" and functionality. The Director of the Master of Arts - Integrated Studies (MAIS) program provided a good deal of the inspiration behind the project as he conferred with Library staff to find better ways to deliver online readings and resources to students. As word spread about the DRR, faculty from other AU Centres came to the Library to ask if certain features could be built in. As a result, the DRR is responsive to end user needs and concerns and this has resulted in the inclusion of various functions: a search engine for searching and retrieving DRR resources across courses, a broken link checker to insure that links to Web-based resources are still valid, the ability to easily search and reuse learning resources, functions that permit the use of hanging indents and italicization for formatting bibliographic citations, and a statistical tracking mechanism that counts the number of times a resource has been accessed.

A number of faculty concerns have arisen and have been addressed. A key issue is the openness of the DRR to public view and to cross-course searching, and the legitimate concern of faculty to protect their intellectual property. Early in the collaboration the Library found it necessary to emphasize that the DRR is about sharing "reading or resource lists", and facilitating access to resources, and is not intended to replace the detailed instructions student receive in the course study guides and assignment manuals. Another area of concern pertains to faculty workload and the entry of resources into the DRR. In some cases faculty have taken this on themselves, but many have delegated to assistants or have asked the Library to enter the data. During the early phases of the project the goal was to stimulate faculty interest and get courses into the DRR, but as the project has expanded the Library has worked with EMD to resolve the data entry issue. The Director of EMD has offered the services of the Educational Media Typesetters.

After the initial design phase of the Digital Reading Room was completed it became the task of the Library to support the DRR and disseminate information. Support Staff are responsible for determining the availability of print based materials and ordering needed material, filling student requests for print based resources and responding to inquiries from learners. The Librarians have been charged with the task 
of resolving access issues, providing instruction and training to students, faculty and staff, and disseminating information about the DRR both internally and externally through workshops, presentations, conferences and papers.

The scope for collaboration has expanded and the Library is a primary participant in an Athabasca University - eduSource Canada project to develop a learning objects repository that provides access to "searchable and reusable digital resources for technology-supported learning" (http://edusource.athabascau.ca/). The Digital Reading Room has been adopted as the model for the repository which is being developed using meta tags that conform to the IEEE Learning Object Metadata (LOM) standards and use the CANCORE implementation guidelines to insure consistency and search capability across other online repositories. A MARC-to-LOM converter (http://marc-lom.athabascau.ca/marc/index.html) that takes a MARC record and converts it into LOM format is in development; enabling XML based digital repositories to interact with MARC based harvested metadata from library systems. The project draws on the expertise of programmers and designers as well as librarians, particularly the cataloguing and metadata knowledge of the Technical Services Librarian.

\section{Benefits to Students}

The DRR improves and enhances access to course reserves, enabling students to access online resources from any location and at any time. The Library's subscribed journal databases are a key source of content for the DRR. The DRR uses persistent URLs to link students directly to full text journal articles. In addition to having quick access to online materials, students need to be aware of the wide range of scholarly materials that are not available electronically. Canadian copyright law requires that permission be obtained in order to scan and mount copyrighted materials online. Faculty tend to avoid this route due to cost and time constraints and have preferred an alternative offered by the DRR. The DRR supports the inclusion of non-digital resources by linking to Web-based request forms. This simplifies the requesting of offline materials, such as books and print based articles. The forms contain full bibliographic information for an item and students need only enter their name, student ID, and mailing address. When a student submits a Web form, a request for the item is e-mailed to the Library Information Desk where staff process the request and mail out the material. This is considerably more convenient for students than the print based Supplementary Materials system that requires them to provide a list of bibliographic citations to the Library by phone or e-mail.

It has long been recognized that people learn in different ways. (Burdett, 2001; Smith \& Woody, 2000; McCarthy, 1997). The Digital Reading Files have the potential to reach visual and auditory learners as they often include resources in different media, such as video and audio clips. Not only are students made aware of the range of resources available for their course, they are also able to search the Digital Reading Files from other courses for additional materials. One of the greatest difficulties that both librarians and educators face is teaching students where they can find relevant information for their papers. The inclusion of faculty selected resources, whether they are from a journal database or the Internet, helps to introduce students to a variety of different material that has been assessed for quality and authority.

To increase the convenience of access to resources in Digital Reading Files, the Library is experimenting with proxy-less access to licensed resources: students enter the course learning management system (e.g. WebCT or Lotus Notes or Bazaar) with login and password and this is their authentication. They are not prompted for a Library ID number when accessing journal database content as they have already been authenticated at the course level. The University's implementation of uPortal will further streamline student access to information and resources, providing students with a personalized interface.

In order to more concretely determine the benefits of the DRR, AU Librarians and the Manager, Special Projects are engaged in a research project to evaluate the impact of the DRR. Semi-structured interviews will be used to assess the effectiveness of the DRR in delivering course and supplementary resources to students and to assess the impact of implementing the DRR into course materials on faculty

and library staff workloads. It can be expected that findings from this research will provide valuable insight into the impact of the DRR on student learning and satisfaction with course resources and the 
successfulness of the DRR in meeting its objectives to increase accessibility of, and stimulate interest in, these resources. This research will highlight any areas in which changes may be required in the current DRR system, from student, faculty or library staff perspectives.

\section{Information Literacy}

Student success is affected by many factors, including technological issues such as access to online resources and the library can help facilitate this through effective e-reserves systems. The Digital Reading Room increases student awareness of the variety of material available to them in digital format by providing them with faculty-selected resources. However, if information literacy is to be achieved, it is also important to provide students with opportunities to search for their own research materials and to develop the skills they need to be successful in this task.

Information literacy is a key goal of librarians and educators alike. We are all aware of the importance of teaching learners the basics of research and writing. In this age of information overload, when more and more materials are becoming available in electronic format, it is essential to teach learners how to construct effective search strategies for library catalogues, journal databases and the World Wide Web, as well as how to navigate the plethora of database platforms and interfaces. As a library in an entirely distance education institution, we are continually faced with the issue of providing the necessary information in an effective manner for students we never meet.

Librarians can play an important role, especially in partnership with teaching faculty, in promoting skills that bring students into the world of scholarship, such as critical thinking, evaluation and reflection. Encouraging students to engage in effective information-seeking behaviours is challenging. To aid students, AU Librarians and Faculty have created a variety of information literacy tools designed to help students become better researchers and information consumers.

\section{Help Centre}

The majority of AU Library information literacy tools are housed in the "Help Centre" on the Library's Web site. The Library is working with faculty to encourage integration of some of these tools into the Digital Reading Files to promote a more independent learner approach to locating information. The Help Centre contains resources created in-house, as well as some carefully chosen resources from other institutions. It contains information about citation styles, e-books, Internet searching, accessing and searching journal databases and library catalogues, and researching and writing papers.

The Library is engaged in a number of projects to develop discipline-specific research guides in collaboration with faculty from the various academic centers at AU. Much of the library instruction in traditional institutions with campus-based classes is done either in face-to-face reference transactions or in library instruction classes offered on campus. Athabasca University's geographic location and the fact that students are located across Canada and internationally, makes in-person instructional opportunities rare. To compensate for this, detailed information and instruction normally imparted in-person is provided through the Library Web site. Because students often learn best not in isolation with a Web tutorial but through interaction with a librarian, the Library provides a toll-free number within North America and reference services via e-mail.

To ensure that research guides are tailored to the disciplines and relevant to students, librarians obtain topics and examples from the collaborating faculty members or from course guides and confer with faculty on questions of evaluation criteria, research methodologies and so on. Search examples and screen shots are developed using databases that are appropriate to the discipline. Undergraduate guides (e.g. http://library.athabascau.ca/help/wmst/intro_wmst.htm) contain information about the steps involved in the research process: from thinking critically about a research topic, to constructing search strategies using a range of online tools, to evaluating information resources, citing them appropriately, and writing an academic paper. The main goals are to help undergraduate students to establish a logical thinking process 
from the beginning and not get overwhelmed by the task of writing a research paper and to provide them with a basic information literacy skill set.

Graduate level guides (e.g. http://library.athabascau.ca/help/mais/main.htm) focus less on basic steps for research and more on the types of resources available in the discipline, including archives and research collections. Whereas the undergraduate guides may include a few examples, primarily from full text databases, undergraduate guides typically deal with a larger number of databases, including abstracting and indexing tools. Collaboration plays an even greater role at this level and the faculty member's subject expertise is essential in directing students to resources that provide students with access to opposing viewpoints and alternative sources, and that the pedagogy for the discipline is soundly entrenched in the guide.

\section{Conclusion}

The Digital Reading Room provides Athabasca University with a means to improve the way course reserves are delivered, facilitating access to learning material in a variety of formats and supporting and promoting use of quality digital resources. Building the DRR has brought many opportunities for collaboration, increasing the Library's visibility within the institution and encouraging an environment in which all partners involved think more proactively about ways to promote student success, including not only access to resources, but also information literacy. 